\title{
Energetic outer radiation belt electron precipitation during recurrent solar activity
}

\author{
Mark A. Clilverd, ${ }^{1}$ Craig J. Rodger, ${ }^{2}$ Tracy Moffat-Griffin, ${ }^{1}$ Emma Spanswick, ${ }^{3}$ \\ Paul Breen, ${ }^{1}$ Frederick W. Menk, ${ }^{4}$ Russell S. Grew, ${ }^{4}$ Kanji Hayashi, ${ }^{5}$ and Ian R. Mann ${ }^{6}$ \\ Received 4 January 2010; revised 1 March 2010; accepted 1 April 2010; published 28 August 2010.
}

[1] Transmissions from three U.S. VLF (very low frequency) transmitters were received at Churchill, Canada, during an event study in May to November, 2007. This period spans four cycles of recurrent geomagnetic activity spaced $\sim 27$ days apart, with daily $\Sigma \mathrm{Kp}$ reaching $\sim 30$ at the peaks of the disturbances. The difference in the amplitude of the signals received during the day and during the night varied systematically with geomagnetic activity, and was used here as a proxy for ionization changes caused by energetic electron precipitation. For the most intense of the recurrent geomagnetic storms there was evidence of electron precipitation from $3<L<7$ for 10-15 days after the peak of the disturbance, as measured by $\Sigma \mathrm{Kp}$ and Dst. This was consistent with the time variation of the fluxes of Polar Operational Environmental Satellites (POES) $>300 \mathrm{keV}$ and $\sim 1 \mathrm{MeV}$ trapped electrons, and also consistent with the daily average ULF (ultralow frequency) Pc1-2 power $(L=3.9)$ from Lucky Lake, Canada, which was elevated during the $\sim 1 \mathrm{MeV}$ electron precipitation period. This suggests that Pc1-2 waves may play a role in outer radiation belt loss processes during this interval. We show that the $>300 \mathrm{keV}$ trapped electron flux from POES is a reasonable proxy for electron precipitation during recurrent high-speed solar wind streams, although it did not describe all of the variability that occurred. While energetic electron precipitation can be described through a proxy such as $\mathrm{Kp}$ or Dst, careful incorporation of time delays for different electron energies must be included. Dst was found to be the most accurate proxy for electron precipitation during the weak recurrent-activity period studied.

Citation: Clilverd, M. A., C. J. Rodger, T. Moffat-Griffin, E. Spanswick, P. Breen, F. W. Menk, R. S. Grew, K. Hayashi, and I. R. Mann (2010), Energetic outer radiation belt electron precipitation during recurrent solar activity, J. Geophys. Res., 115, A08323, doi:10.1029/2009JA015204.

\section{Introduction}

[2] The influence of radiation belt processes on the Earth's atmosphere is currently a topic of intense debate. As energetic particles precipitate into the upper atmosphere they enhance in situ ionization rates [Siskind, 2000], and this results in chemical composition changes as odd nitrogen $\left(\mathrm{NO}_{x}\right)$ and odd hydrogen $\left(\mathrm{HO}_{x}\right)$ compounds are created [Solomon et al., 1982]. $\mathrm{HO}_{x}$ and $\mathrm{NO}_{x}$ take part in the catalytic destruction of ozone and hence change the radiative balance of the atmosphere [Brasseur and Solomon, 2005]. Although

\footnotetext{
${ }^{1}$ British Antarctic Survey, Natural Environment Research Council, Cambridge, UK.

${ }^{2}$ Department of Physics, University of Otago, Dunedin, New Zealand.

${ }^{3}$ Department of Physics and Astronomy, University of Calgary, Calgary, Canada.

${ }^{4}$ School of Mathematical and Physical Sciences, University of Newcastle, Callaghan, Australia.

${ }^{5}$ Department of Earth and Planetary Physics, University of Tokyo, Tokyo, Japan.

${ }^{6}$ Department of Physics, University of Alberta, Edmonton, Canada.
}

Copyright 2010 by the American Geophysical Union. 0148-0227/10/2009JA015204
$\mathrm{HO}_{x}$ is a short-lived species that only acts on ozone in situ, $\mathrm{NO}_{x}$ is long-lived (with a lifetime of days to months) in the absence of photolysis and can therefore be transported horizontally and vertically during its lifetime. This is particularly true in the dark polar wintertime and in the presence of the polar vortex [Randall et al., 2005; Manney et al., 2005]. As such, the products of energetic particle precipitation processes can have a long-lived and distributed effect on the chemistry and radiative balance of the atmosphere [Rozanov et al., 2005; Seppälä et al., 2009].

[3] Energetic proton precipitation occurring during solar proton events (SPEs) is a well-known influence on the atmosphere [Seppälä et al., 2004]. During some intense solar storms, solar protons in the energy range of 1 to $>100 \mathrm{MeV}$ enter the atmosphere in the polar regions, having been guided by the geomagnetic field [Rodger et al., 2006]. Proton flux measurements made from geostationary satellites (i.e., the Geostationary Operational Environmental Satellite (GOES)) have been shown to be good proxies for the flux and energy spectrum of protons entering the atmosphere [Verronen et al., 2005; Clilverd et al., 2005, 2006a]. The highest energy protons can occasionally penetrate as low as 

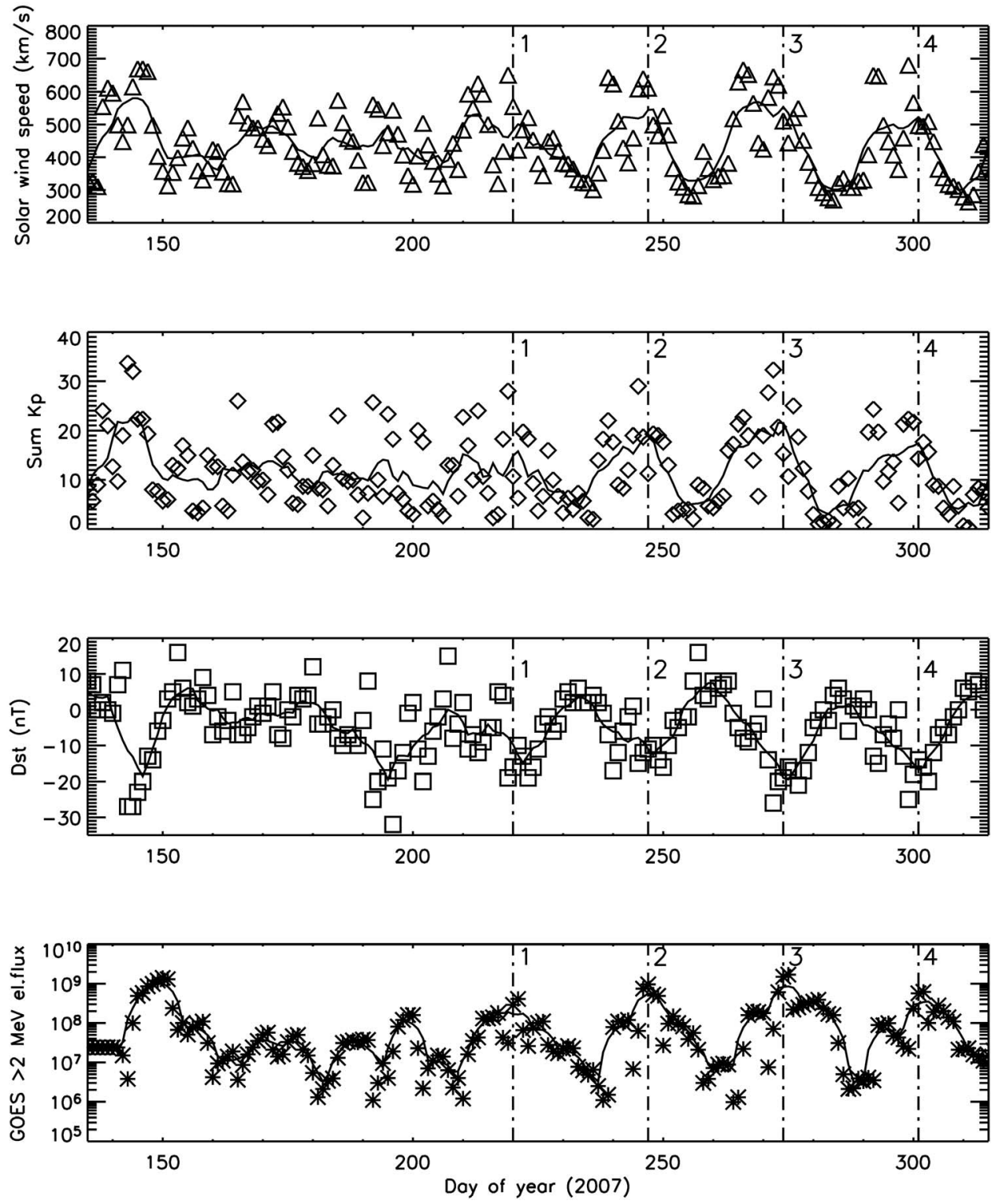

Figure 1. Geomagnetic conditions during May to November 2007. The daily solar wind speed, daily sum Kp, daily Dst, and daily GOES $>2 \mathrm{MeV}$ electron flux are plotted in separate panels. Each panel also shows a 7 day smoothed line (solid line) for each parameter. A 27 day recurrent period of high solar wind, geomagnetic activity, and high electron fluxes is indicted by the dot-dashed vertical lines.

the ground, although typically the lowest altitude influenced is $40-50 \mathrm{~km}$ [Seppälä et al., 2008]. The lower energy protons scatter in the atmosphere at much higher altitudes $(\sim 120 \mathrm{~km}$ for $1 \mathrm{MeV}$ protons), but are still capable of ionizing the atmospheric constituents [Turunen et al., 2009].

[4] However, while SPEs are intense, they are relatively infrequent, and typically only last for a few days [Shea and Smart, 1990; Richardson et al., 2000]. When they do occur, SPEs are more frequent during the 11-year solar cycle maximum than at solar minimum [Borovsky and Denton, 2006]. In contrast, energetic electron precipitation driven by radiation belt processes is less well understood in terms of measurements of the flux and location of electrons entering the atmosphere. Further, there is considerable uncertainty as to the energy spectra of the electron precip- itation, since there are multiple radiation belt processes taking place, such as acceleration and loss by several different VLF (very low frequency) wave-particle interaction processes [Imhof et al., 1992; Blake et al., 1996; Millan et al., 2002; Horne, 2002], and radial transport by ULF (ultralow frequency) waves [Fei et al., 2006 and references therein]. Energy diffusion due to electron gyroresonance with chorus, plasmaspheric hiss, and electromagnetic ion-cyclotron waves (EMIC) have been shown to be key mechanisms for generating relativistic electrons in the region outside of the plasmasphere during geomagnetic storms [e.g., Summers et al., 2007, and references therein]. Omura et al. [2008] describe recent progress in understanding the acceleration of energetic electrons in the outer radiation belt caused by nonlinear wave-particle interactions by the relativistic 
second-order resonance condition for whistler-mode waves. The gyroresonant pitch-angle scattering of electrons by chorus, plasmaspheric hiss, and EMIC waves can lead to significant precipitation into the atmosphere and the net loss of energetic electrons from the outer radiation belt [e.g., Lorentzen et al., 2001; O'Brien et al., 2004; Thorne et al., 2005; Rodger et al., 2007; Rodger et al., 2008].

[5] Recent results have shown that radiation belt acceleration processes are more significant during recurrent highspeed solar wind stream (HSSWS) storms than those occurring during storms driven by coronal mass ejections (CMEs) [Hilmer et al., 2000; Miyoshi and Kataoka, 2005; Vassiliadis et al., 2007]. Radiation belt electron precipitation has been shown to be longer lasting during HSSWS storms than during CMEs [Longden et al., 2008]. HSSWS storms occur more frequently during the declining-minimum phase of the 11-year solar cycle [Borovsky and Denton, 2006]. Generally, radiation belt electron precipitation processes can be thought of as driving electrons into the atmosphere at the mid- to polar latitudes, with a peak occurrence frequency taking place during the declining phase of the 11-year solar cycle. The detailed time variability, energy spectrum, and flux, however, have proved difficult to measure.

[6] Satellite measurements of electron precipitation properties have been available for more than a solar cycle (e. g., the Solar Anomalous and Magnetospheric Particle Explorer (SAMPEX) and the Polar Operational Environmental Satellites (POES)). However, each satellite instrument has some of the following limitations: limitations in spatial or energy resolution, low-energy proton contamination, an inability to adequately resolve the drift-bounce loss cone. These issues result in uncertainties as to the actual loss rates of electrons into the atmosphere when measured from satellites. For example, Rodger et al. [2010] analyzed 10 years of POES data [Evans and Greer, 2004] to provide a description of energetic electron precipitation with a comprehensive study of enhanced loss fluxes from the radiation belts, but with limited energy spectrum resolution.

[7] Ground-based measurements of the lower ionosphere can help contextualize satellite measurements of electron precipitation. Obliquely propagating VLF radio waves can be used to monitor the changes in ionization rate caused by electron precipitation over a great circle path between a transmitter and receiver. The Antarctic-Arctic Radiationbelt (Dynamic) Deposition-VLF Atmospheric Research Konsortium (AARDDVARK) network [Clilverd et al., 2009] makes use of this property to determine the path-integrated effect of electron precipitation in many high-latitude locations around the world. The enhancement in ionization rate as a result of electron precipitation causes changes in the received phase and amplitude of the observed signals, which can be readily compared with the non-disturbed, quiet-day behavior.

[8] In this study, we analyse data from an AARDDVARK receiver located in Churchill, Canada, and concentrate on signals from three U.S. transmitters (with the call signs NAA, NDK, NLK). The signals are used to determine the effects of electron precipitation into the atmosphere over the range $3<L<8$, i.e., where outer radiation belt processes occur. We study the period of May to November 2007, which includes several recurrent HSSWS solar activity cycles, and analyze the Churchill AARDDVARK data in comparison with POES electron flux observations at $>300 \mathrm{keV}$ and $>1 \mathrm{MeV}$. The radio-wave propagation effects observed are then described in terms of the effectiveness of recurrent solar activity in producing energetic electron precipitation into the atmosphere.

\section{Experimental Setup}

[9] Figure 1 shows the geomagnetic conditions during the May to November 2007 period that is studied in this paper. The solar wind speed, daily $\Sigma \mathrm{Kp}$, daily Dst, and daily GOES $>2 \mathrm{MeV}$ electron flux are plotted in separate panels ordered from top to bottom. Each panel also shows a 7 day smoothed line (solid line) for each parameter. The solar wind speed during the study period ranged from $250 \mathrm{~km} / \mathrm{s}$ to $700 \mathrm{~km} / \mathrm{s}$. After day 210, a HSSWS feature appeared which repeated four times within a 27 day period. During this period, the solar wind speeds consistently peaked at $\sim 650 \mathrm{~km} / \mathrm{s}$, dropping to $\sim 250 \mathrm{~km} / \mathrm{s} 10$ days after the peak. The $\Sigma \mathrm{Kp}$ and Dst values followed a very similar pattern to the solar wind speed, with the highest geomagnetic disturbance occurring on the third recurrence of the HSSWS activity. Very similar patterns can be seen in the GOES electron fluxes, where high solar wind and high geomagnetic activity were associated with high electron-flux levels at geostationary orbit. The peak times of the 27 day recurrent activity in solar wind, geomagnetic activity, and high $L=6.6$ electron fluxes are indicted by the dot-dashed vertical lines in Figure 1. For clarity, we have labeled the recurrent storm activity cycles as cycles $1-4$. We note that during the May to November 2007 period studied there were no occasions where elevated solar proton flux occurred which could potentially mask the effects of energetic electron precipitation into the high-latitude atmosphere.

[10] To study the electron precipitation effects into the atmosphere during the May to November 2007 period, this paper uses narrowband, subionospheric, very low frequency (VLF) data spanning $24-25 \mathrm{kHz}$ that were received at Churchill, Canada (located at $58^{\circ} 44^{\prime} \mathrm{N}, 93^{\circ} 49^{\prime} \mathrm{W} ; L=7.6$ ). The Churchill site is part of the AARDDVARK network [Clilverd et al., 2009]. (For further information, see the description of the array provided at http://www.physics.otago.ac.nz/space/AARDDVARK_homepage.htm). The transmitters studied have the call signs NAA $(24.0 \mathrm{kHz}$; located at $\left.44^{\circ} 39^{\prime} \mathrm{N}, 67^{\circ} 17^{\prime} \mathrm{W} ; L=2.9\right)$, NDK $\left(25.2 \mathrm{kHz}\right.$; located at $46^{\circ}$ $\left.22^{\prime} \mathrm{N}, 98^{\circ} 20^{\prime} \mathrm{W} ; L=3.2\right)$, and NLK $\left(24.8 \mathrm{kHz}\right.$; located at $48^{\circ}$ $\left.12^{\prime} \mathrm{N}, 121^{\circ} 55^{\prime} \mathrm{W} ; L=2.9\right)$. The effects of changing ionization conditions in the mesosphere due to energetic particle precipitation can be observed along the propagation path between a transmitter and a receiver. Subionospheric propagation is sensitive to ionization located below $\sim 90 \mathrm{~km}$ altitude. The effect of increased ionization on the propagating signals can be seen as either an increase or decrease in signal amplitude or phase, depending on the modal mixture of each signal observed [Barr et al., 2000; Clilverd et al., 2007].

[11] Figure 2 shows the location of the Churchill radio wave receiver site (diamond) and the transmitter-receiver paths that are studied during the event period (the NAA, NDK, and NLK transmitter locations are shown by the circles). The propagation paths span the range $3<L<8$, effectively integrating the subionospheric electron precipi- 


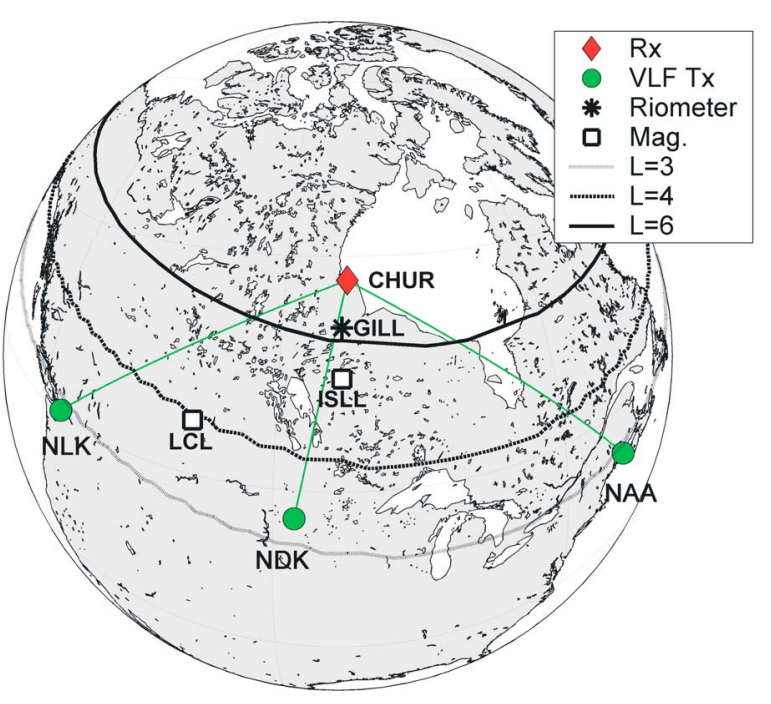

Figure 2. The location of subionospheric propagation paths in the northern hemisphere from VLF transmitters (circles) to the AARDDVARK receiver site at Churchill (diamond). $L$-Shell contours for $L=3, L=4$, and $L=6$ are shown. The location of the Gillam riometer, as well as the Lucky Lake and Island Lake magnetometers are also indicated (asterisk and squares, respectively).

tation along the paths from the whole of the outer radiation belt. The three paths analysed are relatively short, the transmitters are very similar in frequency, and their geomagnetic latitudes are also very similar. As such, we combine the data from the three transmitters in order to confirm that large scale precipitation effects are occurring on all three paths at the same time.

[12] In this study we also make use of particle measurements by the Space Environment Monitor-2 (SEM-2) instrument package onboard the POES spacecraft which are in Sun-synchronous orbits at altitudes of $\sim 800-850 \mathrm{~km}$ [Evans and Greer, 2004]. SEM-2 includes the Medium Energy Proton and Electron Detector (MEPED), in addition to the Total Energy Detector (TED). Together these instruments monitor electron fluxes from $50 \mathrm{eV}$ up to $2700 \mathrm{keV}$. We make use of SEM-2 observations from up to four POES spacecraft. All POES data are available from http://poes. ngdc.noaa.gov/data/; while the full-resolution data have $2 \mathrm{~s}$ time resolution, we work with the $16 \mathrm{~s}$ resolution ASCII files. The $0^{\circ}$-pointing detectors are mounted on the threeaxis-stabilized POES spacecraft so that the centre of each detector field of view is outward along the local zenith, parallel to the Earth-center-to-satellite radial vector. Another set of detectors termed " $90^{\circ}$-minus" are mounted approximately perpendicular to the $0^{\circ}$ detector. In addition, there is also a set of omnidirectional measurements made from a dome detector which is mounted parallel to the $0^{\circ}$ detectors. The detectors pointing in the $0^{\circ}$ and $90^{\circ}$ directions are $\pm 15^{\circ}$ wide, while the omnidirectional dome detectors (termed "omni") are $\pm 60^{\circ}$ wide. For the $L$-shells we consider, the $90^{\circ}$-detector appears to primarily respond to trapped electrons, and hence we refer to it as the "trapped detector". In Figure 3, we show the $>300 \mathrm{keV}, 90^{\circ}$ POEStrapped electron fluxes during the study period of May to November 2007, indicating the influence of HSSWS on the energetic electron fluxes in the outer radiation belt (Figure 3, solar wind speed shown in upper panel). The black shading in Figure 3 indicates a lack of data.

[13] Ground-based magnetometer data are also analyzed in this study, particularly for ULF phenomena in the higher part of this frequency band (i.e., up to $5 \mathrm{~Hz}$ ). Figure 2 shows the locations of the magnetometers at Lucky Lake (labeled "LCL") and Island Lake (labeled "ISLL). The Island Lake magnetometer is part of the Canadian Array for Realtime Investigations of Magnetic Activity (CARISMA) network [Mann et al., 2008]. The Narod fluxgate magnetometers there provide a data stream sampled at $8 \mathrm{~Hz}$. At Lucky Lake, a search coil magnetometer operated by the University of Tokyo provides data sampled at $10 \mathrm{~Hz}$. We determine the daily average ULF intensity, having filtered over the bandwidth of interest. During the study period in 2007, we used $1-22 \mathrm{mHz}$ from the Island Lake magnetometer in the Pc4-5 range, and we used $0.1-5 \mathrm{~Hz}$ from the Lucky Lake magnetometer in the Pc1-2 range.

\section{Results}

\subsection{Energetic Electron Precipitation}

[14] When energetic electron precipitation ionizes the atmosphere it typically changes the propagation conditions for transmitter signals by modifying the upper boundary condition of the subionospheric waveguide. The lower boundary, being the land or sea surface, is regarded as remaining constant with time. Under non-disturbed ionospheric conditions, the upper boundary conditions of the subionospheric waveguide will vary throughout the day as the Sun rises and sets. Typically we would expect to observe higher amplitude transmitter signals during the night and lower amplitudes during the day, with deep minima during the sunrise and sunset periods [e.g., Clilverd et al., 1999].

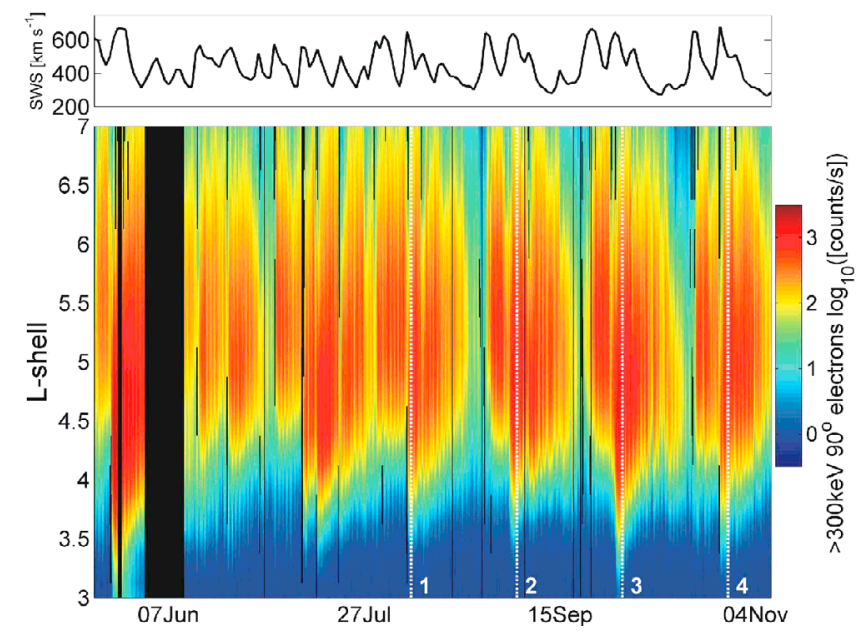

Figure 3. The $>300 \mathrm{keV} 90^{\circ}$ POES trapped electron fluxes during the study period in 2007 showing the presence of recurrent HSSWS influence on the energetic electron fluxes in the outer radiation belt. Figure 3 (top) indicates the daily average solar wind speed. Black shading indicates a lack of data. The periods of recurrent geomagnetic activity identified in Figure 1 are indicated by the vertical dashed lines. 

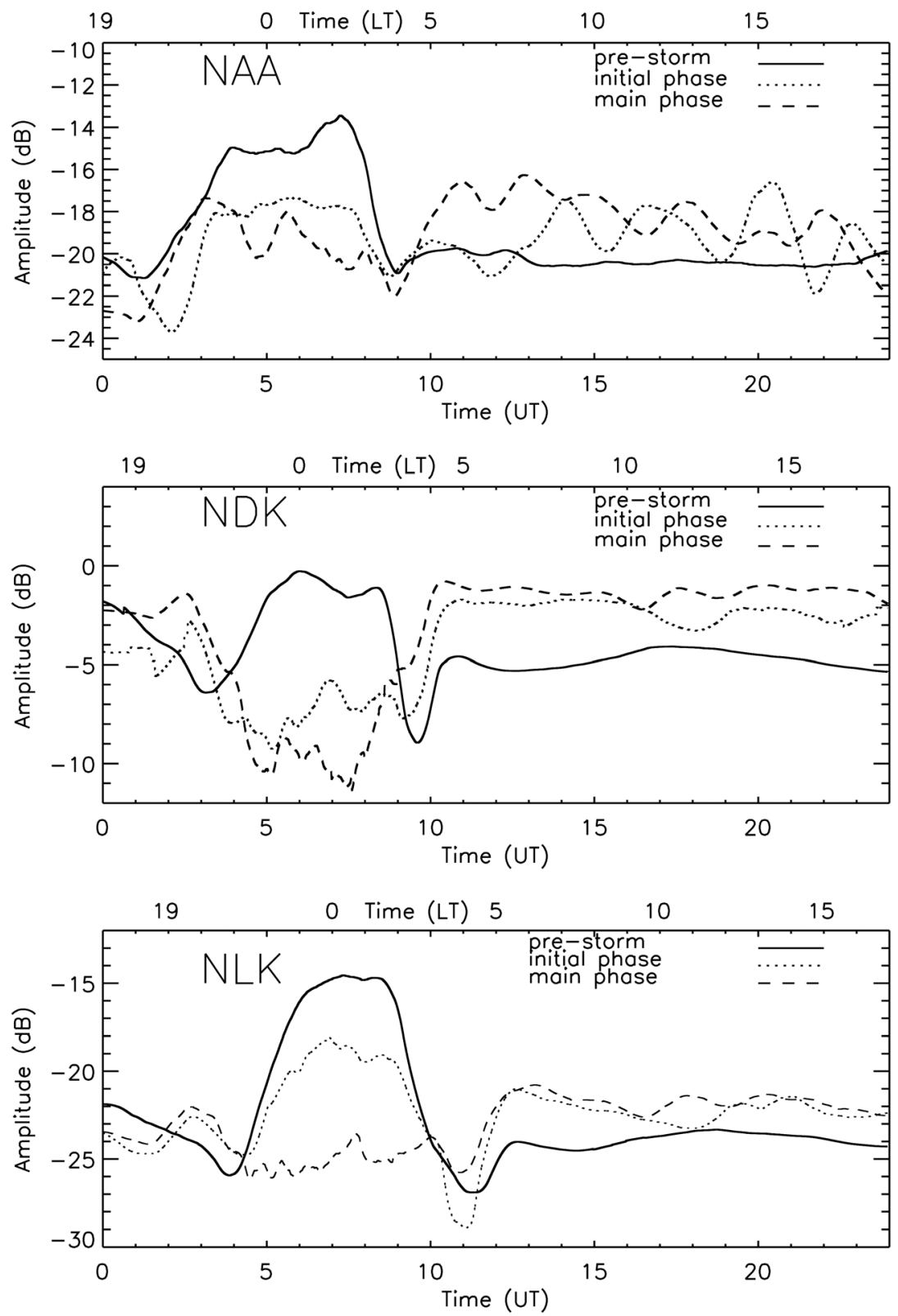

Figure 4. Typical diurnal variations in the amplitude of NAA, NDK, and NLK signals received at Churchill during several phases of a geomagnetic storm in May 2007. In each panel, there are three lines representing a non-disturbed, pre-storm variation (solid line, 18 or 21 May 2007); an initial storm-phase variation (dotted line, 23 or 24 May 2007); and a main storm-phase variation (dashed line, 26 May 2007). Local time for the midpoint of each path is shown at the top of each panel.

[15] In Figure 4, we show the typical diurnal variations in the amplitude of the three transmitters, NAA, NDK, and NLK, received at Churchill during several phases of a geomagnetic storm which occurred on 22-25 May 2007. In each panel there are three lines representing a non-disturbed, pre-storm variation (solid line); an initial storm-phase variation (dotted line); and a main storm-phase variation (dashed line). The pre-storm data shown are from either 18 or 21 May 2007 . The selection is primarily influenced by the need for the transmitter to be operating the entire day and not undergoing any off-air maintenance. The initial storm data are taken from either 23 or 24 May 2007, and the main phase data are taken from 26 May 2007. The storm time variations from all three transmitters follow basically the same pattern, i.e., during a geomagnetic storm, the nighttime amplitude decreases and the daytime amplitude increases relative to the non-disturbed behavior. This is consistent with increased ionization at altitudes that define the upper boundary for subionospheric propagation of $\sim 25 \mathrm{kHz}$ radio waves, i.e., altitudes below $\sim 85 \mathrm{~km}$ during the night and below $\sim 72 \mathrm{~km}$ during the day [McRae and Thomson, 2000; Thomson and Clilverd, 2007]. This suggests an experimental sensitivity to electron precipitation energies $>50 \mathrm{keV}$ at night and $>200 \mathrm{keV}$ during the day [Turunen et al., 2009]. 

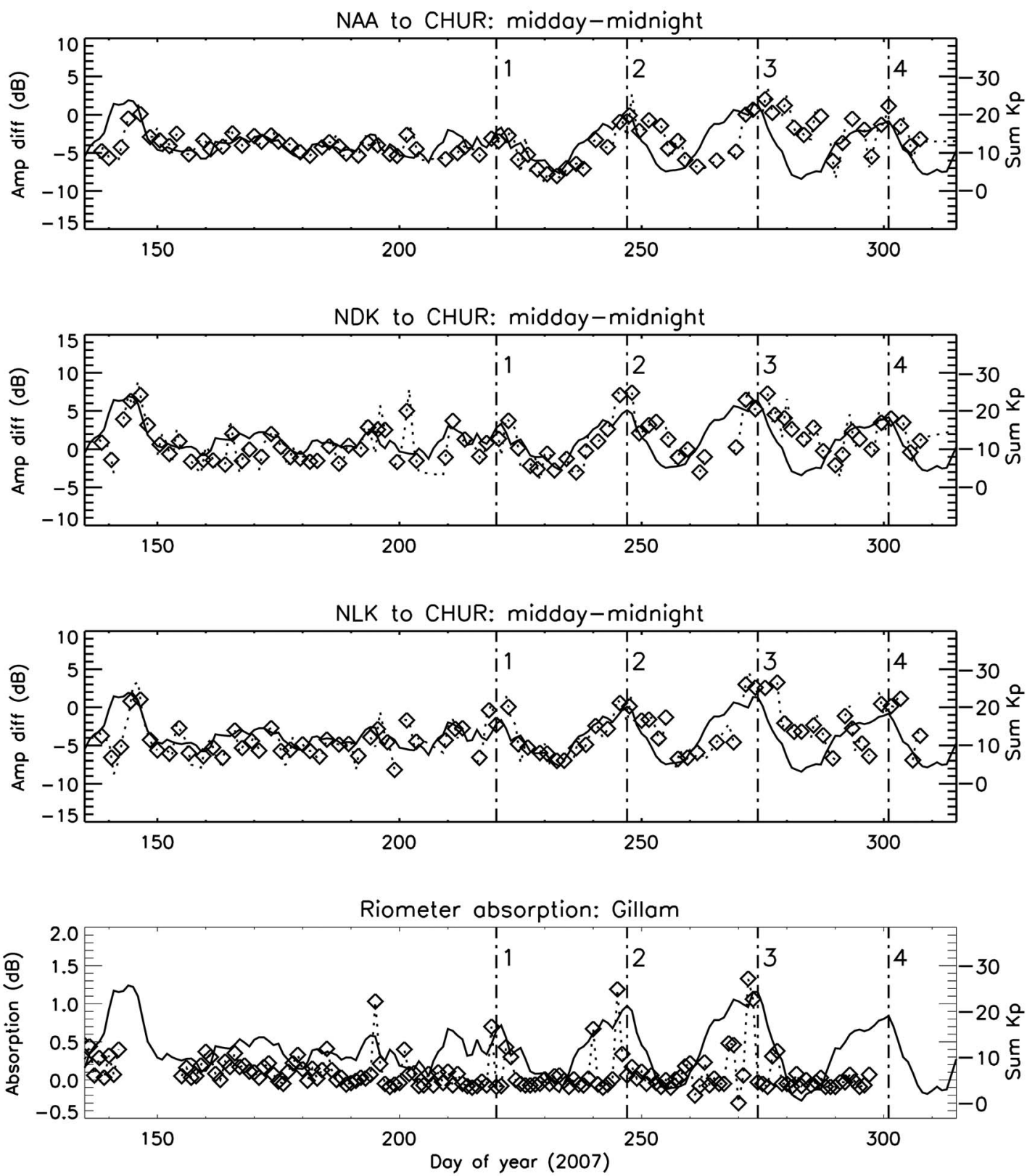

Figure 5. The day-night amplitude difference (diamonds) for the three transmitters from May to November 2007. Also shown in each panel is the 7 day smoothed daily-sum Kp (solid line), scaled to fit the difference in amplitude variations, and the vertical dot-dashed lines as shown in Figure 1, which represent the peaks of the recurrent storm activity cycles $1-4$. The lower panel shows the average daytime riometer absorption from Gillam (diamonds, $L=6.3$ ), located in central Canada (see Figure 2).

Figures 5-9 show the difference in amplitude between the daytime average and the nighttime average (Amp diff). During non-disturbed periods, nighttime amplitudes are higher than daytime amplitudes, and thus the difference in amplitude is negative. During disturbed periods, the difference in amplitude becomes more positive as the nighttime amplitudes become lower than the daytime amplitudes. This behavior has been observed previously in connection with enhanced ionization events such as solar proton events [Clilverd et al., 2006b], has been modelled successfully in terms of general ionization enhancements [Clilverd et al.,
2007], and has been used to study changes of ionization for observation periods of many months [Clilverd et al., 2009]. The phases of the transmitter signals also show distinct changes as a result of electron precipitation, with the most significant change being observed as a phase advance during the nighttime. However, in this paper we confine ourselves to discussing amplitude changes, as they are more readily analyzed over the multi-month period analyzed in this paper, and consistent with previous analysis of this type [Clilverd et al., 2007]. 

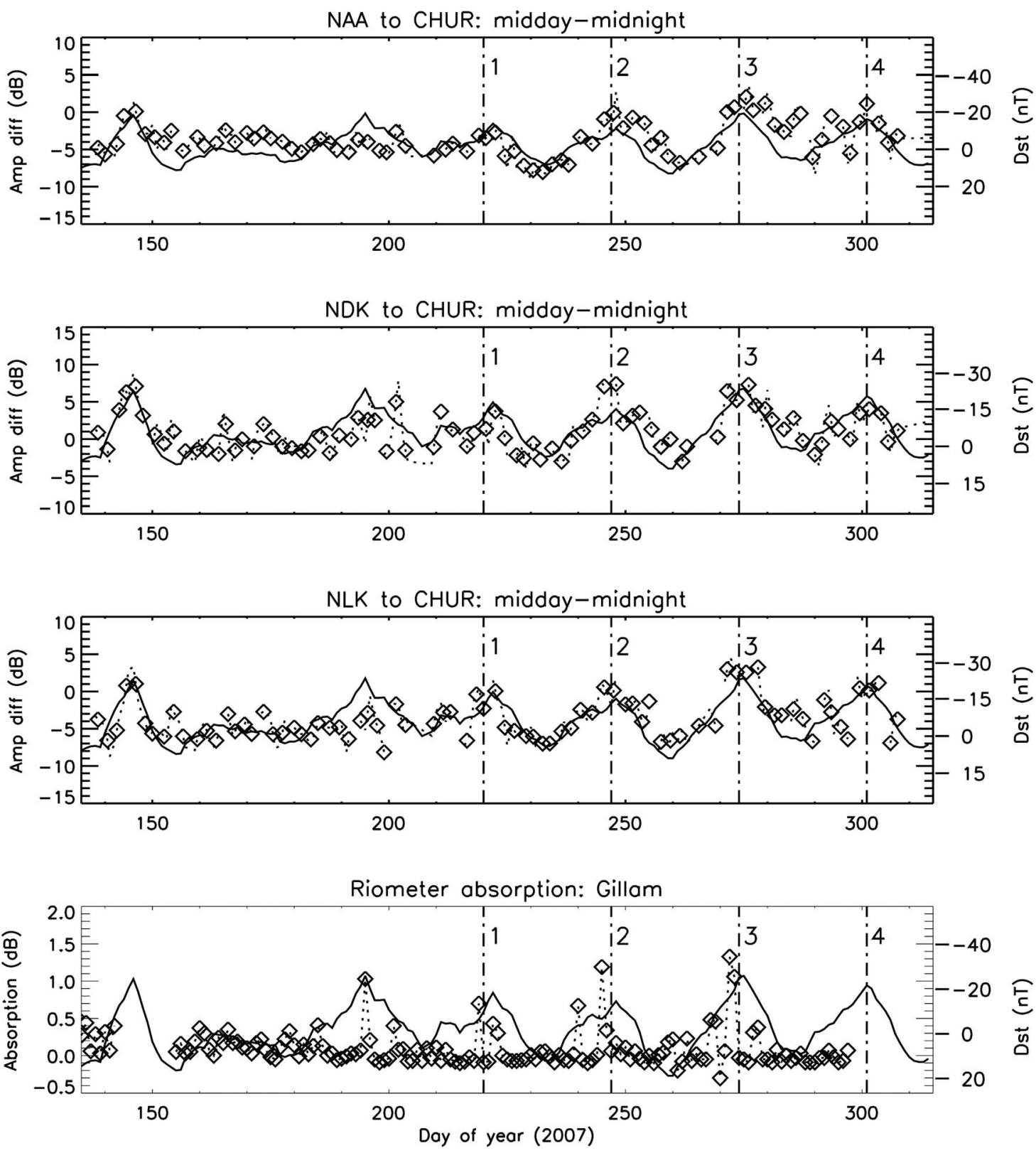

Figure 6. The day-night amplitude difference (diamonds) for the three transmitters from May to November 2007, in the same format as Figure 5. Also shown in each panel is the 7 day smoothed daily Dst (solid line), scaled to fit the difference in amplitude variations.

\subsection{Comparison With $\Sigma K \mathbf{K}$}

[16] Figure 5 shows the day-night amplitude difference (diamonds) for the three transmitters from 19 May 2005 to November 2007. The data stopped on 5 November 2007 (day 308) because of a long-term system fault at Churchill. The panels are arranged to represent the average longitude of the transmitter-receiver paths, ordered with the easternmost longitude in the top panel, i.e., NAA. Also plotted in each panel is the 7 day smoothed daily sum $\mathrm{Kp}$ (solid line), scaled to fit the difference in amplitude variations, and the vertical dot-dashed lines, as shown in Figure 1, to represent the peaks of the recurrent storm activity cycles $1-4$. The bottom panel in Figure 5 shows the average daytime riometer absorption from Gillam $(L=6.3)$, located in central Canada. These results should be representative of electron precipitation from the outer radiation belts in the energy range of 30$200 \mathrm{keV}$ [Little and Leinbach, 1959; Browne et al., 1995].

[17] Figure 5 shows that as the geomagnetic activity varies so does the amplitude difference for each transmitter, indicating the presence of varying energetic electron precipitation resulting from enhanced geomagnetic activity. Following the large storm that occurred near the end of May 2007 (day 147, shown in Figure 4), a period of relatively quiet geomagnetic activity occurred until the onset of the recurrent activity starting on day $\sim 210$. During the four cycles of the recurrent activity for which we have data, the amplitude difference shows a consistent positive response to 

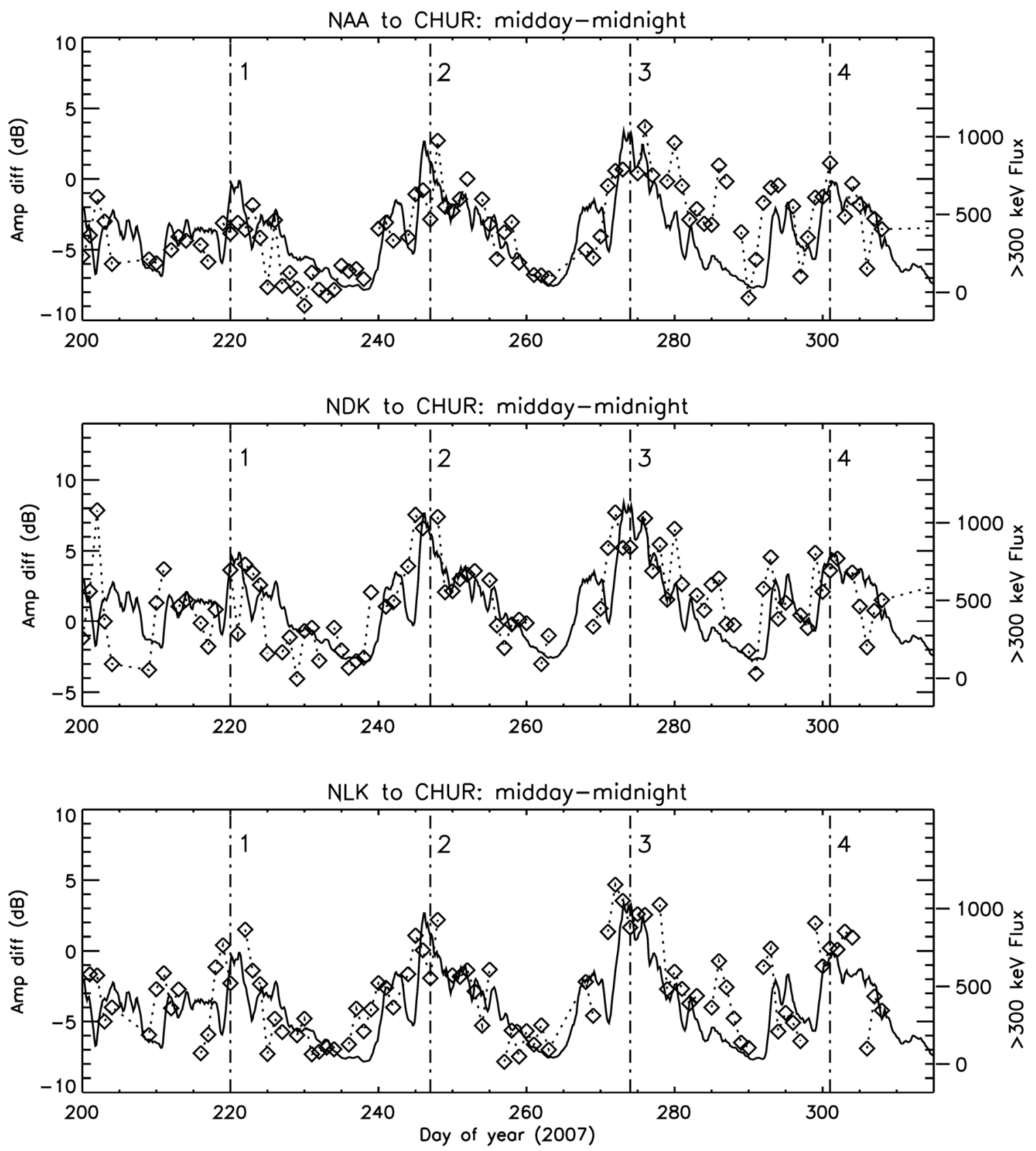

Figure 7. The day-night amplitude difference for NAA, NDK, and NLK, received at Churchill in 2007 (diamonds joined by dotted line) compared with the $3<L<7$ averaged POES $>300 \mathrm{keV}$ trapped electron flux for the same period (solid line). Recurrent solar activity cycles are labeled as cycles 1-4.

the increased geomagnetic activity and only returns to normal levels in between the cycle peaks. However, particularly following the most intense geomagnetic activity periods (cycles 2 and 3, occurring at days $\sim 250$ and $\sim 280$ ), the amplitude differences remain high for $\sim 10-15$ days afterward, despite the fact that geomagnetic activity has subsided to lower levels, particularly for $\mathrm{Kp}$. This is true for the observation paths sampled by all three transmitters. The lower panel in Figure 5 shows that the riometer response does not behave in a similar way, peaking in absorption briefly, and apparently responding only during the time of the peak of the geomagnetic activity. This therefore suggests that the energy of the electron precipitation driving the elevated VLF radio wave amplitude difference response is $>200 \mathrm{keV}$, and thus the energy would not be registered by the riometer.

\subsection{Comparison With Dst}

[18] Although $\mathrm{Kp}$ is a well known geomagnetic activity index, we can also compare the amplitude difference variations with another index of geomagnetic disturbance, Dst. Dst is a measure of the energy density of the ring current calculated from the average value of the horizontal component of the geomagnetic field measured at four nearequatorial geomagnetic observatories. Typically Dst shows a negative deviation during geomagnetic storms. Recurrent 

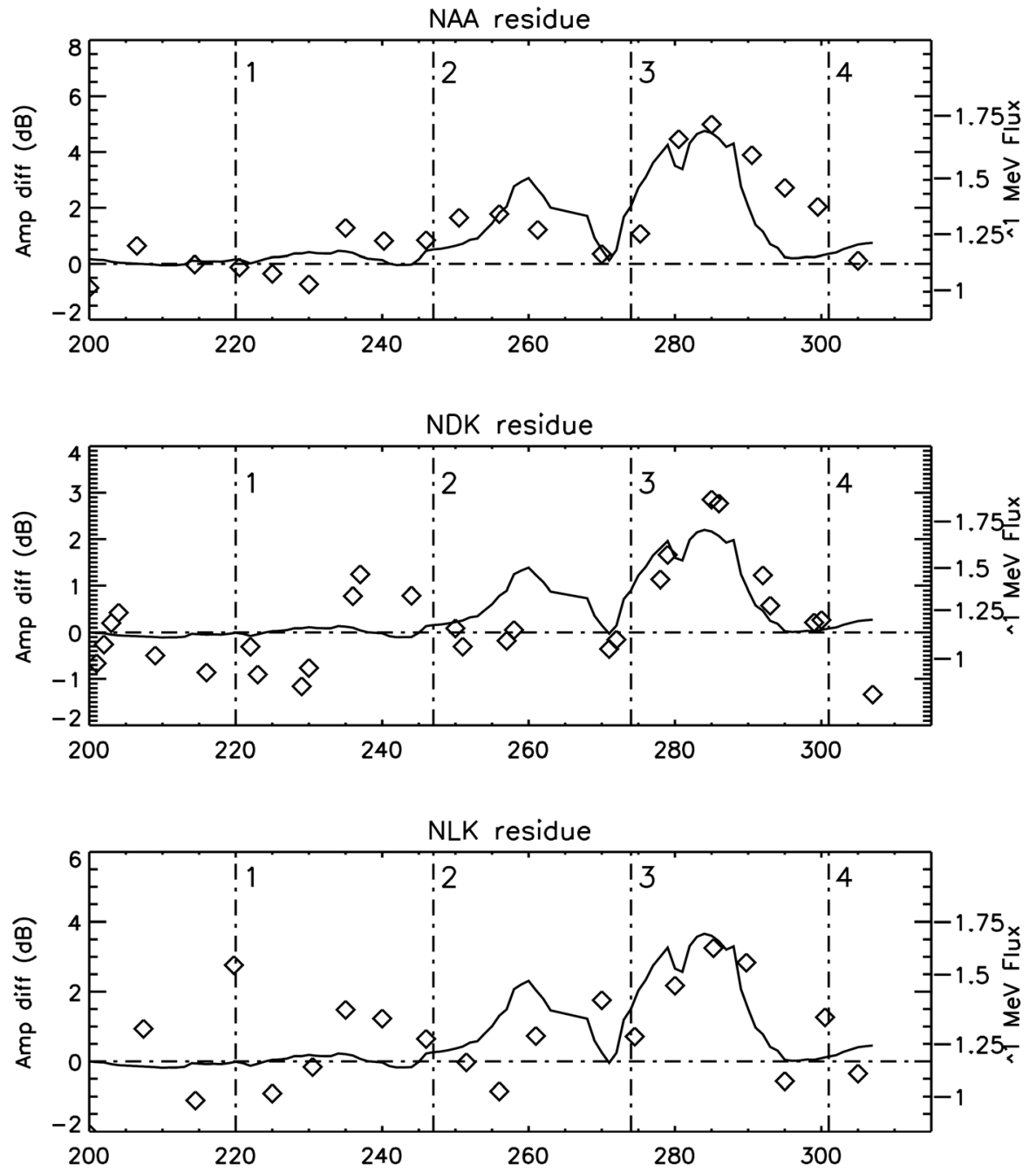

Figure 8. The remnant amplitude difference values (diamonds) during the study period, each panel represents one of the three transmitters. Also plotted is the POES $\sim 1 \mathrm{MeV}$ trapped flux from the omni detector (solid line) averaged from $3<L<7$. Recurrent solar activity cycles are labeled as cycles $1-4$.

geomagnetic storms typically show Dst values of $\sim-50 \mathrm{nT}$ [Borovsky and Denton, 2006]. In Figure 6, we show the amplitude difference data for each of the three transmitters and the riometer absorption from Gillam in the same format as Figure 5. However, for Figure 6 we include the smoothed daily Dst variation, scaled to fit the amplitude data. In order to do this we invert the Dst scale. The figure shows that Dst can be a good indicator of the recurrent storm effects on the amplitude difference data. By comparison with Figure 5, it is clear that the Dst index captures the onset of the storm effect more accurately than $\mathrm{Kp}$. This is particularly noticeable for the storm in May 2007 (day 147), and recurrent storm cycle 3 . Dst is also more accurate in representing the decline in the recurrent storm effect than $\mathrm{Kp}$, although the NAA transmitter in particular still shows some elevated amplitude difference values after Dst has returned to nonstorm levels.

[19] The lower panel in Figure 6 shows that the riometer response does not match the variation in Dst particularly closely. In much the same way as with $\mathrm{Kp}$, the riometer absorption only shows any significant response at the approximate times of the peaks in Dst activity.

\subsection{Comparison With Satellite Data}

[20] Since the VLF radio waves from NAA, NDK, and NLK propagate beneath the region of the subionospheric waveguide that is influenced by electron precipitation from the outer radiation belt, we compare the amplitude difference variations with the average $3<L<7$ electron flux variations observed from POES. Figure 7 shows the amplitude difference for each transmitter (diamonds joined by dotted line) and the $3<L<7$ average POES 90 $>300 \mathrm{keV}$ trapped fluxes (solid line). As in previous figures the recurrent cycles in geomagnetic activity are labeled cycles by $1-4$, with the timing of the peak taken from Figure 1 and indicated by vertical dot-dashed lines. From Figure 7 we can see that the behavior of the amplitude difference from each transmitter is well represented by the variations in the $>300 \mathrm{keV}$ fluxes. This is particularly true for cycles 1 and 2, but not for the latter half of cycle 3 where there are enhanced amplitude differences even after the $>300 \mathrm{keV}$ electron 

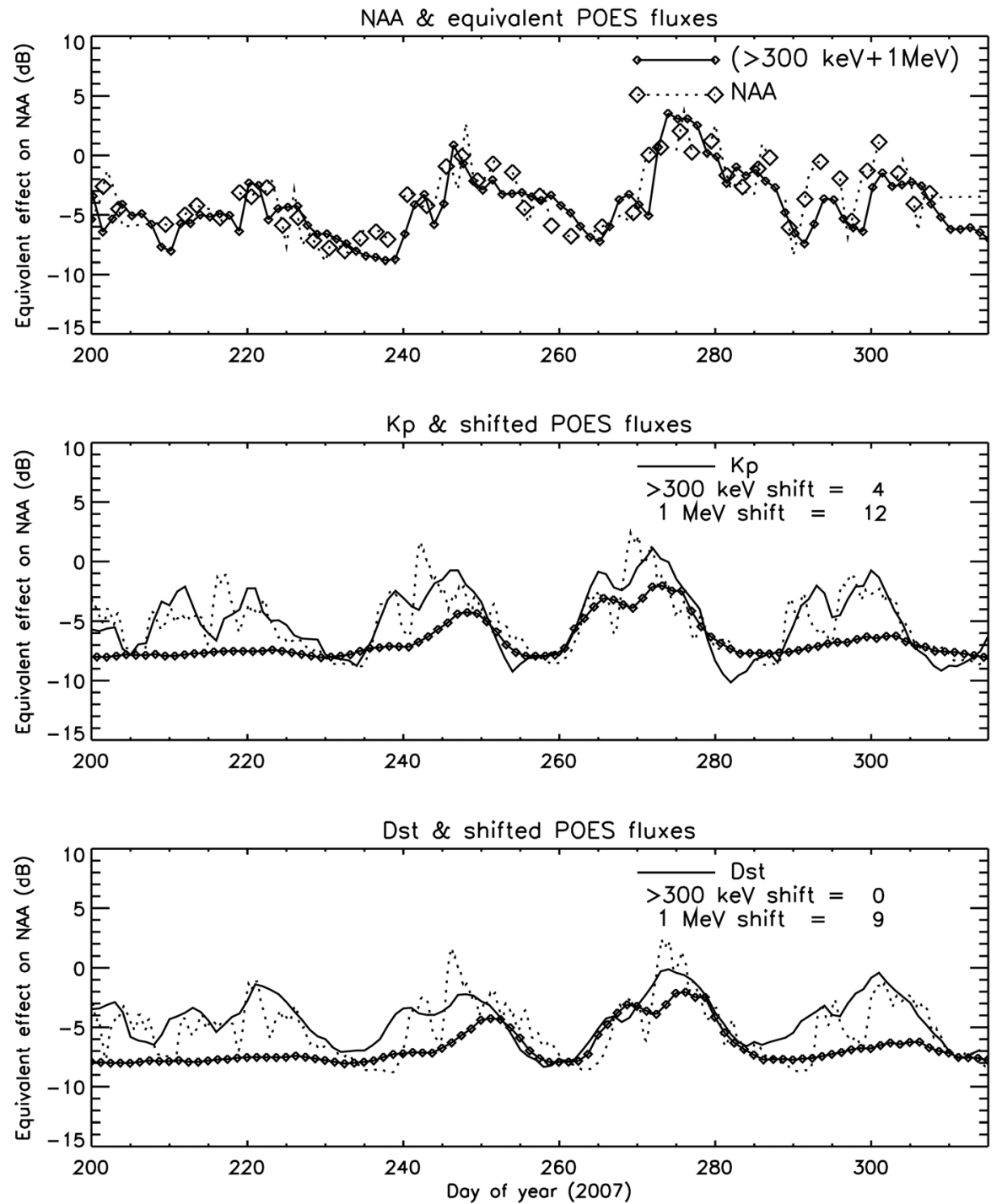

Figure 9. (top) Comparison of the NAA day-night amplitude difference (dotted line, open diamonds) with the result of combining the equivalent POES $>300 \mathrm{keV}$ trapped electron flux determined from Figure 7 and the equivalent $\sim 1 \mathrm{MeV}$ trapped electron flux determined from Figure 8 (solid line, solid diamonds). (middle) The equivalent smoothed daily sum $\mathrm{Kp}$ (solid line) and the $>300 \mathrm{keV}$ fluxes (dotted line), shifted earlier by 4 days, and the $\sim 1 \mathrm{MeV}$ fluxes (solid line, diamonds), shifted earlier by 12 days. (bottom) The equivalent smoothed daily Dst (solid line) and the $>300 \mathrm{keV}$ fluxes (dotted line), shifted earlier by 0 days, and the $\sim 1 \mathrm{MeV}$ fluxes (solid line, diamonds), shifted earlier by 9 days.

fluxes have returned to near-zero levels, particularly around day 285. As this is not observed in the riometer data (shown in Figures 5 and 6) or the $>300 \mathrm{keV}$ fluxes, we investigate the possibility that there is even more energetic electron precipitation happening during this period at energies significantly beyond $300 \mathrm{keV}$, i.e., at around $1 \mathrm{MeV}$, which is not correlated with lower energy $>300 \mathrm{keV}$ precipitation.

[21] As there is a large component of the difference amplitudes that is well described by the $>300 \mathrm{keV}$ fluxes, we can remove that effect by scaling the fluxes as shown in Figure 7 and then subtracting them from the difference values. The result is shown in Figure 8, where the diamonds represent the remnant amplitude difference values during the study period, and each panel shows one of the three transmitters. Once again, we look for consistency between the three transmitter data sets to confirm that we are not just seeing noise. In each panel we also plot the POES $\sim 1 \mathrm{MeV}$ onmi detector trapped flux (solid line), averaged from $3<$ $L<7$. The $1 \mathrm{MeV}$ electron fluxes are measured as a contaminant of the $16 \mathrm{MeV}$ proton dome onmi detector, but as there were no solar proton events during our study period, we can be confident that the fluxes are primarily due to trapped energetic electrons [Rodger et al., 2010]. Figure 8 shows that the remnant amplitude differences vary in a similar way to the $\sim 1 \mathrm{MeV}$ electron fluxes for all three transmitters, particularly during the $\sim 10$ to 15 days after recurrent activity cycle 3 . Thus 
it appears most likely that the long-lived VLF amplitude disturbance seen in our observations is due to a combination of $>300 \mathrm{keV}$ and relativistic $(\sim 1 \mathrm{MeV})$ electron precipitation, with a spectrum that hardens with time such that there is an increasing fraction of relativistic electrons.

[22] Following the approach of Rodger et al. [2010, see Figure 8], who saw energy dependant time delays ranging from 1 to 12 days in the POES energetic electron data after recurrent storms, we consider the possibility that the enhanced difference amplitudes observed on all three transmitters after cycle 3 could be due to a delayed enhancement of high-energy electron fluxes relative to lower-energy electrons. In Figure 9 (upper panel) we plot the day-night amplitude difference for the NAA transmitter (dotted line, open diamonds) and compare them with the results of adding together the equivalent amplitude effect of the POES $>300 \mathrm{keV}$ trapped electron flux determined from Figure 7 and the $\sim 1 \mathrm{MeV}$ trapped electron flux determined from Figure 8 (solid line, solid diamonds). The combination of the equivalent amplitude effect of the two energy ranges provides a reasonable description of the amplitude difference data in the upper panel of Figure 9. The middle panel of Figure 9 shows the smoothed daily sum Kp (solid line), with the $>300 \mathrm{keV}$ fluxes shifted earlier by 4 days and the $\sim 1 \mathrm{MeV}$ fluxes shifted earlier by 12 days. The smoothed daily sum Kp (solid line) is not shifted in time at all. A very clear phasing of several recurrent activity cycles can be seen, suggesting that there is an increased delay for increasing electron energies, which is the same as the results of Rodger et al. [2010], who attributed this delay to the effects of wave-particle interaction processes taking place in the outer radiation belt following recurrent geomagnetic activity. The lower panel of Figure 9 shows the smoothed daily Dst (solid line), with the $>300 \mathrm{keV}$ fluxes shifted earlier by 0 days and the $\sim 1 \mathrm{MeV}$ fluxes shifted earlier by 9 days. This panel suggests that Dst is a good representation of the amplitude difference effects on NAA, as represented by the POES $>300 \mathrm{keV}$ trapped electron flux, that requires 0 days offset. But a 9 day offset to the $\sim 1 \mathrm{MeV}$ fluxes is required to capture the full amplitude difference variation represented by the combination of $>300 \mathrm{keV}$ fluxes and $\sim 1 \mathrm{MeV}$ fluxes.

\subsection{Comparison With ULF Power Variations}

[23] Mathie and Mann [2000] demonstrated that $\mathrm{MeV}$ electron-flux enhancements at geostationary orbit $(L=6.6)$ followed days of elevated Pc5 ULF wave power in the outer magnetosphere, suggesting that Pc5 pulsations were involved in the acceleration of electrons to $\mathrm{MeV}$ energies. An association between solar wind speed and Pc5 ULF wave power was shown for the first half of 1995, particularly associations involving recurrent fast solar wind speed streams. In this study, Figure 1 shows that our study period involves recurrent high speed solar wind streams that have associated enhancements in geostationary $\mathrm{MeV}$ electron fluxes, suggesting the presence of enhanced ULF wave power. Furthermore, Rodger et al. [2008] showed that the precipitation of $\sim 1 \mathrm{MeV}$ electrons into the atmosphere at $L=$ 4-5 was associated with electromagnetic ion-cyclotron waves (EMIC) observed in the ULF Pc1-2 range during periods of moderate geomagnetic activity. Summers and
Thorne [2003] examined the mechanism of electron pitchangle diffusion by gyroresonant interaction with EMIC waves as a cause of relativistic electron precipitation loss from the outer radiation belt. They concluded that electrons with energy $\leq 1 \mathrm{MeV}$ can be removed from the outer radiation belt by EMIC wave scattering during a magnetic storm over a time scale of several hours to a day. Therefore we investigate the variation of Pc4-5 and Pc1-2 wave power observed at magnetometer sites located in Canada in the $L$-shell range between those of the VLF transmitters and the Churchill receiver. The time variations of the Pc4-5 and Pc1-2 wave power may allow us to infer some causative linkage to the delayed electron precipitation effects that are shown by the VLF radio wave data in Figure 5.

[24] Figure 10 shows the daily average ULF intensity in the Pc4-5 range $(1-22 \mathrm{mHz})$ from the Island Lake fluxgate magnetometer (ISLL, $L=5.2$ ), and ULF intensity in the Pc1-2 range $(0.1-5 \mathrm{~Hz})$ from the Lucky Lake search coil magnetometer (LCL, $L=3.9,10 \mathrm{~Hz}$ ) during the study period in 2007. In the plot, the y-axis units for ISLL and LCL are arbitrary and different and cannot be compared. These magnetometer sites are marked as squares in Figure 2. Also shown in Figure 10 are the daily $\Sigma \mathrm{Kp}$ and daily Dst variations and vertical lines to indicate the peak of the recurrent solar wind cycles. The variation of the Pc4-5 wave intensity (a proxy for power) was closely associated with the variation of $\Sigma \mathrm{Kp}$, which we show in Figure 1 to be phaselocked to the solar wind speed. These observations of Pc4-5 wave intensity are consistent with the results of Mathie and Mann [2000]. The Pc4-5 intensity was not enhanced during days 280-285, when the VLF signals suggest the occurrence of electron precipitation. The variation of the Pc1-2 wave intensity is not as clearly associated with the $\Sigma \mathrm{Kp}$ variation, but does show enhanced levels during days 280-285 that are consistent with the subionospheric VLF data.

[25] The interpretation of Figure 10 suggests that while Pc4-5 wave power is enhanced at the same time as the solar wind speed and $\Sigma \mathrm{Kp}$ it does not appear to play any role in the delayed electron precipitation that is observed with the VLF data. The association of high Pc4-5 wave power with high levels of geostationary $\mathrm{MeV}$ electron fluxes is consistent with the conclusion of Mathie and Mann [2000] in terms of the ULF waves accelerating electrons to high energy in the magnetosphere. Conversely, the period of enhanced Pc1-2 wave intensity is consistent with the electron precipitation observed with the VLF data. This suggests that Pc1-2 wave power is involved in the electron loss processes from the magnetosphere, dumping electrons into the atmosphere. The location of the Lucky Lake magnetometer site, from which the Pc1-2 wave power was determined, is close to the outer edge of the plasmasphere ( $L$ $=\sim 4$ ), and so the electron precipitation may be associated with EMIC waves located near the plasmapause [Fraser and Nguyen, 2001]. Further work is required to accurately locate the region of electron precipitation and model the VLF response to it. Although the energy of electron precipitation that has been associated with EMIC waves is $\sim 1 \mathrm{MeV}$ [Rodger et al., 2008], and we have shown in this study that enhanced fluxes of $\sim 1 \mathrm{MeV}$ electrons are also observed by the POES satellites, it is as yet unclear why the loss process takes place with such a delay compared with the geomagnetic storm and the associated electron acceleration processes. 

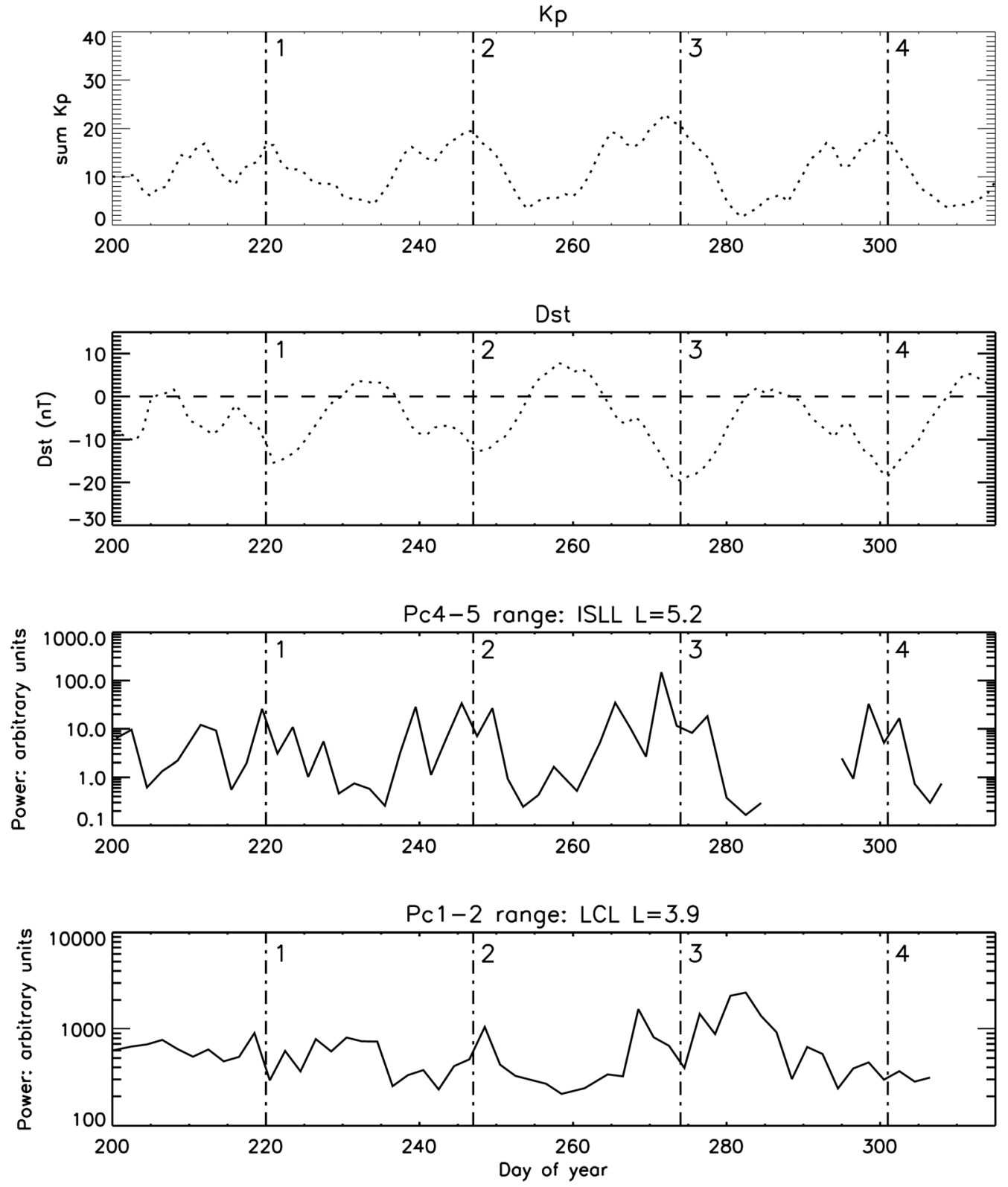

Figure 10. Daily average ULF Pc4-5 and Pc1-2 power received at Island Lake (ISLL, $L=5.2$ ) and Lucky Lake (LCL, $L=3.9)$ compared with the variation of geomagnetic activity $\left(\sum \mathrm{Kp}\right)$ and daily Dst. Periods of recurrent geomagnetic activity are indicated by the vertical dashed lines.

\section{Discussion and Summary}

[26] In 2007, we operated a radio receiver at Churchill, Canada from May to November. During that period, the phase and amplitude from three U.S. $\sim 25 \mathrm{kHz}$ transmitters were recorded (call signs NAA, NDK, and NLK). Geomagnetic activity during the study period was generally low, as would be expected for the minimum of the 11 year solar activity cycle. However, there were four cycles of recurrent geomagnetic activity spaced $\sim 27$ days apart that were generated by a corotating interaction region, with daily $\Sigma K p$ reaching $\sim 30$ at the peaks of the disturbances and daily Dst reaching $\sim-30 \mathrm{nT}$. The difference in the amplitude of the transmitters between daytime and nighttime varied with geomagnetic activity and was used as a proxy for sub- ionospheric ionization changes caused by energetic electron precipitation during the geomagnetic storms. We used the day-night amplitude differences to investigate the variation of electron precipitation from the outer radiation belt during the recurrent geomagnetic storms.

[27] For the most intense of the recurrent geomagnetic storms, there was evidence of electron precipitation between $L=3$ and $L=7$ for 10-15 days after the peak of the disturbance, as measured by sum Kp and daily Dst. The lesser disturbances showed precipitation effects that lasted for 510 days after the peak disturbance. This was found to be consistent with the time variation of the fluxes of $>300 \mathrm{keV}$ and $\sim 1 \mathrm{MeV}$ trapped electrons measured by POES. Using equivalent amplitude effects of the POES $>300 \mathrm{keV}$ and $\sim 1 \mathrm{MeV}$ trapped electron fluxes, it was possible to explain 
the majority of the time variation in the difference amplitudes from all three transmitters during the recurrent storm activity. This suggests that the POES-trapped fluxes in this energy range can be used as a reasonable proxy for the electron precipitation fluxes in the bounce loss cone, which are much harder to measure and subject to more influence of proton contamination [Rodger et al., 2010]. However, we should note that this conclusion has only been shown to hold for recurrent storm activity, and on a daily average basis. Other geomagnetic activity influences, and in particular shorter time scales, may not show such a relationship. Further analysis of radio wave data from Churchill is planned to address this issue.

[28] In combining the POES $>300 \mathrm{keV}$ and $\sim 1 \mathrm{MeV}$ trapped electron fluxes to reproduce the day-night amplitude difference variations observed, we determined that the recurrent storm activity acted on the different energies with different delay times. Relative to the smoothed daily $\Sigma \mathrm{Kp}$, the $>300 \mathrm{keV}$ electron fluxes peaked after a delay of 4 days, while the $\sim 1 \mathrm{MeV}$ electron fluxes peaked after a delay of 12 days. This is consistent with the findings of Rodger et al. [2010], who found this type of increasingly delayed response with increasing electron energy in several periods of recurrent storm activity during the declining phase of solar cycle 23 , typically averaging 2 days delay for $>300 \mathrm{keV}$ and 8 days delay for $\sim 1 \mathrm{MeV}$ electrons.

[29] Relative to the smoothed daily Dst, the POES $>300 \mathrm{keV}$ electron fluxes peaked after a delay of 0 days, while the POES $\sim 1 \mathrm{MeV}$ electron fluxes peaked after a delay of 9 days, showing Dst to be a good measure of the effect of $>300 \mathrm{keV}$ electron fluxes.

[30] The daily average ULF intensity over the Pc4-5 range from Island Lake (ISLL, $L=5.2$ ) and ULF intensity over the Pc1-2 range from Lucky Lake (LCL, $L=3.9$ ), both situated between the VLF transmitters and the Churchill receiver, show variations during the study period. The ULF Pc4-5 wave intensity was not elevated during the period in which $\sim 1 \mathrm{MeV}$ electron precipitation was identified, but varied in phase with the solar wind speed as with previous findings. The ULF Pc1-2 wave intensity was elevated during the $\sim 1 \mathrm{MeV}$ electron precipitation period following the third and most intense of the recurrent geomagnetic activity cycles, and is consistent with a picture that involves Pc1-2 waves in radiation belt loss processes. The presence of time delays for higher energy electrons is consistent with a "cartoon" view of electron acceleration processes, for example through cyclotron interactions with whistler-mode waves, such that electrons are accelerated to progressively higher energies over time [Horne et al., 2005]. The precipitation of $\sim 1 \mathrm{MeV}$ electrons into the atmosphere appears to be more associated with the delayed appearance of a loss mechanism involving Pc1-2 waves (i.e., EMIC waves) than as a direct consequence of an ever present loss mechanism that is purely responding to the increase in high-energy fluxes through electron acceleration. Clearly, both electron acceleration and loss processes need to be active in order to generate significant levels of energetic electron precipitation into the atmosphere, and further investigation beyond this event study are required to understand the detailed balance between these processes.

[31] The importance of energetic electron precipitation into the atmosphere has been demonstrated by many authors [e.g., Rozanov et al., 2005; Seppälä et al., 2009]. A key mechanism is the production of chemicals at high latitudes during the polar winter, which can catalytically destroy ozone and hence change the radiative balance of the atmosphere [Brasseur and Solomon, 2005]. In global climate models energetic electron precipitation must either be represented by measurements from the ground or spacecraft, or by a proxy such as Kp or Ap. In this study, we have shown that for one type of geomagnetic activity (recurrent HSSWS) the $>300 \mathrm{keV}$ trapped electron flux from POES is a reasonable measurement to use, although it does not capture all of the variability of the electron precipitation from the outer radiation belt. We have also shown that it may be possible to describe energetic electron precipitation using a proxy such as Kp or Dst, but we note that careful incorporation of time delays for different electron energies must be considered, particularly for Kp. Further work is needed to determine the energetic electron precipitation fluxes and spectra that are suggested by the $>300 \mathrm{keV}$ trapped fluxes.

[32] Acknowledgments. The authors would like to acknowledge the support and enthusiasm of LeeAnn Fishback and Carley Basler at the Churchill Northern Studies Centre, Churchill, Canada. MAC and TM-G would also like to acknowledge NERC funding as part of the climate program at the British Antarctic Survey. The magnetometer data from Lucky Lake was provided under the STEP Polar Network program (http://step-p. dyndns.org/ khay/). CARISMA is operated and deployed by the University of Alberta and funded by the Canadian Space Agency.

[33] Masaki Fujimoto thanks Viacheslav Pilipenko and another reviewer for their assistance in evaluating this paper.

\section{References}

Barr, R., D. L. Jones, and C. J. Rodger (2000), ELF and VLF radio waves, J. Atmos. Sol. Terr. Phys., 62, 1689-1718.

Blake, J. B., M. D. Looper, D. N. Baker, R. Nakamura, B. Klecker, and D. Hovestadt (1996), New high temporal and spatial resolution measurements by SAMPEX of the precipitation of relativistic electrons, Adv. Space Res., 18(8), 171-186.

Borovsky, J. E., and M. H. Denton (2006), Differences between CMEdriven storms and CIR-driven storms, J. Geophys. Res., 111, A07S08, doi:10.1029/2005JA011447.

Brasseur, G., and S. Solomon (2005), Aeronomy of the Middle Atmosphere, 3rd. ed., D. Reidel Publ. Co., Dordrecht, Netherlands.

Browne, S., J. K. Hargreaves, and B. Honary (1995), An imaging riometer for ionospheric studies, Elect. Comm. Eng. J., 7, 209-217.

Clilverd, M. A., N. R. Thomson, and C. J. Rodger (1999), Sunrise effects on VLF signals propagating over a long north-south path, Radio Sci., 34 (4), 939-948.

Clilverd, M. A., C. J. Rodger, T. Ulich, A. Seppälä, E. Turunen, A. Botman, and N. R. Thomson (2005), Modeling a large solar proton event in the southern polar atmosphere, J. Geophys. Res., 110, A09307, doi:10.1029/ 2004JA010922.

Clilverd, M. A., A. Seppälä, C. J. Rodger, N. R. Thomson, P. T. Verronen, E. Turunen, Th. Ulich, J. Lichtenberger, and P. Steinbach (2006a), Modeling polar ionospheric effects during the October-November 2003 solar proton events, Radio Sci., 41, RS2001, doi:10.1029/2005RS003290.

Clilverd, M. A., A. Seppälä C. J. Rodger, P. T. Verronen, and N. R. Thomson (2006b), Ionospheric evidence of thermosphere-to-stratosphere descent of polar $\mathrm{NO}_{x}$, Geophys. Res. Lett., 33, L19811, doi:10.1029/2006GL026727. Clilverd, M. A., A Seppälä, C J Rodger, N. R. Thomson, J. Lichtenberger, and P. Steinbach (2007), Temporal variability of the descent of high-altitude $\mathrm{NO}_{X}$, J. Geophys. Res., 112, A09307, doi:10.1029/2006JA012085.

Clilverd, M. A., et al. (2009), Remote sensing space weather events: The AARDDVARK network, Space Weather, 7, S04001, doi:10.1029/ 2008SW000412.

Evans, D. S., and M. S. Greer (2004), Polar Orbiting Environmental Satellite Space Environment Monitor-2: Instrument descriptions and archive data documentation, NOAA Tech. Mem. 93, 47 p., version 1.4, Space Weather Predict. Cent., Boulder, Colo. 
Fei, Y., A. A. Chan, S. R. Elkington, and M. J. Wiltberger (2006), Radial diffusion and MHD particle simulations of relativistic electron transport by ULF waves in the September 1998 storm, J. Geophys. Res., 111, A12209, doi:10.1029/2005JA011211.

Fraser, B. J., and T. S. Nguyen (2001), Is the plasmapause a preferred source region of electromagnetic ion cyclotron waves in the magnetosphere?, J. Atmos. Sol. Terr. Phys. 63, 1225-1247.

Hilmer, R. V., G. P. Ginet, and T. E. Cayton (2000), Enhancement of equatorial energetic electron fluxes near $L=4.2$ as a result of high speed solar wind streams, J. Geophys. Res., 105(A10), 23,311-23,322.

Horne, R. B. (2002), The contribution of wave-particle interactions to electron loss and acceleration in the Earth's radiation belts during geomagnetic storms, in Review of Radio Science: 1999-2002 URSI, edited by W. R. Stone, pp. 801-828, John Wiley, New York.

Horne, R. B., R. M. Thorne, S. A. Glauert, J. M. Albert, N. P. Meredith and R. R. Anderson (2005), Timescale for radiation belt electron acceleration by whistler mode chorus waves, J. Geophys. Res., 110, A03225, doi: 10.1029/2004JA010811.

Imhof, W. L., R. M. Robinson, H. L. Collin, J. R. Wygant, and R. R. Anderson (1992), Simultaneous measurements of waves and precipitating electrons in the outer radiation belt, Geophys. Res. Lett., 19(24), 2437-2440.

Little, C. G., and H. Leinbach (1959), The riometer: a device for the continuous measurements of ionospheric absorption, Proc. IRE, 37 , $315-320$.

Longden, N., M. H. Denton, and F. Honary (2008), Particle precipitation during ICME-driven and CIR-driven geomagnetic storms, J. Geophys. Res., 113, A06205, doi:10.1029/2007JA012752.

Lorentzen, K., M. Looper, and J. Blake (2001), Relativistic electron microbursts during the GEM storms, Geophys. Res. Lett., 28(13), 2573-2576.

Mann, I. R., et al. (2008), The upgraded CARISMA magnetometer array in the THEMIS era, Space Sci. Rev., 141, pp. 413-451, doi:10.1007/ s11214-008-9457-6.

Manney, G. L., K. Kruger, J. L. Sabutis, S. A. Sena, and S. Pawson (2005), The remarkable 2003-2004 winter and other recent warm winters in the Arctic stratosphere since the late 1990s, J. Geophys. Res., 110, D04107, doi:10.1029/2004JD005367.

Mathie, R. A., and I. R. Mann (2000), A correlation between extended intervals of ULF wave power and storm-time geosynchronous relativistic electron flux enhancements, Geophys. Res. Lett., 27, 3261-3264.

McRae, W. M., and N. R. Thomson (2000), VLF phase and amplitude: Daytime ionospheric parameters, J. Atmos. Sol. Terr. Phys., 62(7), 609-618.

Millan, R. M., R. P. Lin, D. M. Smith, K. R. Lorentzen, and M. P. McCarthy (2002), X-ray observations of $\mathrm{MeV}$ electron precipitation with a balloon-borne germanium spectrometer, Geophys. Res. Lett., 29(24), 2194, doi:10.1029/2002GL015922.

Miyoshi, Y., and R. Kataoka (2005), Ring current ions and radiation belt electrons during geomagnetic storms driven by coronal mass ejections and corotating interaction regions, Geophys. Res. Lett., 32, L21105, doi:10.1029/2005GL024590.

O'Brien, T. P., M. D. Looper, and J. B. Blake (2004), Quantification of relativistic electron microburst losses during the GEM storms, Geophys. Res. Lett., 31, L04802, doi:10.1029/2003GL018621.

Omura, Y., Y. Katoh, and D. Summers (2008), Theory and simulation of the generation of whistler-mode chorus, J. Geophys. Res., 113, A04223, doi:10.1029/2007JA012622.

Randall, C. E., et al. (2005), Stratospheric effects of energetic particle precipitation in 2003-2004, Geophys. Res. Lett., 32, L05802, doi:10.1029/ 2004GL022003.

Richardson, I. G., E. W. Cliver, and H. V. Cane (2000), Sources of geomagnetic activity over the solar cycle: Relative importance of coronal mass ejections, high-speed streams, and slow solar wind. J. Geophys. Res., 105(A8), 18,203-18,213.

Rodger, C. J., M. A. Clilverd, P. T. Verronen, T. Ulich, M. J. Jarvis, and E. Turunen (2006), Dynamic geomagnetic rigidity cutoff variations during a solar proton event, J. Geophys. Res., 111, A04222, doi:10.1029/ 2005JA011395.

Rodger, C. J., M. A. Clilverd, N. R. Thomson, R. J. Gamble, A. Seppälä, E. Turunen, N. P. Meredith, M. Parrot, J. A. Sauvaud, and J.-J. Berthelier (2007), Radiation belt electron precipitation into the atmosphere: Recovery from a geomagnetic storm, J. Geophys. Res., 112, A11307, doi:10.1029/ 2007JA012383.

Rodger, C. J., T. Raita, M. A. Clilverd, A. Seppälä, S. Dietrich, N. R. Thomson, and T. Ulich (2008), Observations of relativistic electron precipitation from the radiation belts driven by EMIC Waves, Geophys. Res. Lett., 35, L16106, doi:10.1029/2008GL034804.
Rodger, C. J., M. A. Clilverd, J. Green, and M.-M. Lam (2010), Use of POES SEM-2 observations to examine radiation belt dynamics and energetic electron precipitation in to the atmosphere, J. Geophys. Res., 115, A04202, doi:10.1029/2008JA014023.

Rozanov, E., L. Callis, M. Schlesinger, F. Yang, N. Andronova, and V. Zubov (2005), Atmospheric response to $\mathrm{NO}_{y}$ source due to energetic electron precipitation, Geophys. Res. Lett., 32, L14811, doi:10.1029/2005GL023041.

Seppälä, A., P. T. Verronen, E. Kyrölä, S. Hassinen, L. Backman, A. Hauchecorne, J. L. Bertaux, and D. Fussen (2004), Solar proton events of October-November 2003: Ozone depletion in the Northern hemisphere polar winter as seen by GOMOS/Envisat, Geophys. Res. Lett., 31 (19), L19107, doi:10.1029/2004GL021042.

Seppälä, A., M. A. Clilverd, C. J. Rodger, P. T. Verronen, and E. Turunen (2008), The effects of hard-spectra solar proton events on the middle atmosphere, J. Geophys. Res., 113, A11311, doi:10.1029/2008JA013517.

Seppälä, A., C. E. Randall, M. A. Clilverd, E. Rozanov, V. L. Harvey, and C. J. Rodger (2009), Geomagnetic activity and polar surface air temperature variability, J. Geophys. Res., 114, A10312, doi:10.1029/ 2008JA014029.

Shea, M. A., and D. F. Smart (1990), A summary of major solar proton events, Solar Phys., 127(2), 297-320.

Siskind, D. E. (2000), On the coupling between the middle and upper atmospheric odd nitrogen, in Atmospheric Science Across the Stratopause, Geophys. Mongr. Ser., vol. 123, edited by D. E. Siskind, S. D. Eckermann, and M. E. Summers, pp. 101-116, AGU, Washington, D. C.

Solomon, S., G. C. Reid, R. G. Roble, and P. J. Crutzen (1982), Photochemical coupling between the thermosphere and the lower atmosphere: 1. Odd nitrogen from 50 to $120 \mathrm{~km}, J$. Geophys. Res., 87, 7206-7220.

Spanswick, E., E. Donovan, and G. Baker (2005), Pc5 modulation of high energy electron precipitation: Particle interaction regions and scattering efficiency, Ann. Geophys., 23, 1533-1542.

Summers, D., and R. M. Thorne (2003), Relativistic electron pitch-angle scattering by electromagnetic ion cyclotron waves during geomagnetic storms, J. Geophys. Res., 108(A4), 1143, doi:10.1029/2002JA009489.

Summers, D., R. L. Mace, and M. A. Hellberg (2005), Pitch-angle scattering rates in planetary magnetospheres, J. Plasma Phys., 71(3), 237.

Summers, D., B. Ni, and N. P. Meredith (2007), Timescales for radiation belt electron acceleration and loss due to resonant wave-particle interactions: 2. Evaluation for VLF chorus, ELF hiss, and EMIC waves, J. Geophys. Res., 112, A04207, doi:10.1029/2006JA011993.

Thomson, N. R., M. A. Clilverd, and W. M. McRae (2007), Nighttime ionospheric D region parameters from VLF phase and amplitude, J. Geophys. Res., 112, A07304, doi:10.1029/2007JA012271.

Thorne, R. M., T. P. O'Brien, Y. Y. Shprits, D. Summers, and R. B. Horne (2005), Timescale for $\mathrm{MeV}$ electron microburst loss during geomagnetic storms, J. Geophys. Res., 110, A09202, doi:10.1029/2004JA010882.

Turunen, E., P. T. Verronen, A. Seppälä, C. J. Rodger, M. A. Clilverd, J. Tamminen, C. F. Enell, and T. Ulich (2009), Impact of different precipitation energies on $\mathrm{NO}_{x}$ generation during geomagnetic storms, J. Atmos Sol. Terr. Phys., 71, pp. 1176-1189, doi:10.1016/j.jastp.2008.07.005.

Vassiliadis, D., I. R. Mann, S. F. Fung, and X. Shao (2007), Ground Pc3Pc5 wave power distribution and response to solar wind velocity variations, Planet. Space Sci., 55 (6), 743-754.

Verronen, P. T., A. Seppälä, M. A. Clilverd, C. J. Rodger, E. Kyrölä, C. Enell, T. Ulich, and E. Turunen (2005), Diurnal variation of ozone depletion during the October-November 2003 solar proton events, J. Geophys. Res., 110, A09S32, doi:10.1029/2004JA010932.

P. Breen, M. A. Clilverd, and T. Moffat-Griffin, British Antarctic Survey, Natural Environment Research Council, High Cross, Madingley Road, Cambridge CB3 0ET, UK. (pbree@bas.ac.uk; macl@bas.ac.uk; tmof@bas.ac.uk)

R. S. Grew and F. W. Menk, School of Mathematical and Physical Sciences, University of Newcastle, Callaghan, NSW, 2308, Australia. (fred.menk@newcastle.edu.au; russell.grew@gmail.com)

K. Hayashi, Department of Earth and Planetary Physics, University of Tokyo, Tokyo 113, Japan. (qyi05527@nifty.ne.jp)

I. R. Mann, Department of Physics, University of Alberta, Edmonton, AB T6G 2J1, Canada. (imann@phys.ualberta.ca)

C. J. Rodger, Department of Physics, University of Otago, PO Box 56, Dunedin, New Zealand. (crodger@physics.otago.ac.nz)

E. Spanswick, Department of Physics and Astronomy, University of Calgary, 2500 University Dr., Calgary, AB T2N 1N4, Canada. (emma@ phys.ucalgary.ca) 